\title{
Synergistic Effect on Corrosion Inhibiton Efficiency of Ginger Affinale Extract in Controlling Corrosion of Mild Steel in Acid Medium
}

\author{
Ananth Kumar Subramanian, Sankar Arumugam*, Kumaravel Mallaiya ${ }^{\dagger}$, and Rameshkumar Subramaniam ${ }^{\dagger}$ \\ Kandaswami Kandar's College, P. velur, Namakkal-638 182, India. *E-mail: surchem2010@gmail.com \\ ${ }^{\dagger} P S G$ College of Technology Peelamedu, Coimbatore 641 004, India \\ (Received April 8, 2013; Accepted September 27, 2013)
}

\begin{abstract}
The corrosion inhibition nature of Ginger affinale extract for the corrosion of mild steel in $0.5 \mathrm{~N} \mathrm{H}_{2} \mathrm{SO}_{4}$ was investigated using weight loss, electrochemical impedance and potentiodynamic polarization methods. The results revealed that Ginger affinale extract acts as a good corrosion inhibitor in $0.5 \mathrm{~N} \mathrm{H}_{2} \mathrm{SO}_{4}$ medium. The inhibition efficiency increased with an increase in inhibitor concentration. The inhibition could be attributed to the adsorption of the inhibitor on the steel surface.
\end{abstract}

Key words: Inhibitor, Weight loss, Impedance, Polarization, Ginger affinale

\section{INTRODUCTION}

Corrosion inhibitors are chemical compounds usually used in small concentrations whenever a metal is in contact with an aggressive medium. The presence of such compounds controls the corrosion process and keeps its rate to a minimum and thus reduces the economic losses due to metallic corrosion. The chemical compounds that could be used for this purpose may be organic or inorganic. However, any chemical compound can't be used as a corrosion inhibitor. There are some requirements for the compounds to act as corrosion inhibitor. Regarding the chemical structure and chemical behavior, an inorganic compound must be able to oxidize the metal, forming a passive layer on its surface. On the other hand, a molecule of an organic compound must have some features to act as a corrosion inhibitor. Among these, the molecule may have a large structure, double bonds, an active center or group, etc. These features make the molecule to cover a large area of a metal surface with a firmly attached film. Apart from the structural aspects, there are also economic and environmental considerations. Thus, since the whole subject of corrosion is about its destructive economical effect, the inhibitor used, must be cheap. Furthermore, due to the recent increasing awareness of green chemistry, it must be a nontoxic and environmentally friendly. One of the sources of these cheap and clean inhibitors is plants. Plant parts contain several compounds that satisfy the requirements of a good corrosion inhibitor. Many recent studies ${ }^{1-8}$ have adopted this trend using naturally occurring substances. This work is devoted to examine the corrosion inhibition ability of the aqueous extract of ginger (Ginger affinale) for the corrosion of mild steel in $0.5 \mathrm{~N} \mathrm{H}_{2} \mathrm{SO}_{4}$ by Weight loss measurements, electrochemical impedance spectroscopic, potentiodynamic polarization and surface studies.

\section{MATERIALS AND METHODS}

\section{Preparation of Extract}

A methanolic extract of ginger affinale was prepared by boiling powdered ginger affinale with methanol,then gangues were removed by filtration. The extract was used as stock solution of inhibitor.

\section{Preparation of Specimens}

Mild steel specimens $(0.022 \% \mathrm{~S}, 0.038 \% \mathrm{Mn}, 0.027 \% \mathrm{P}$, $0.086 \mathrm{C}$ ) of dimensions $1.0 \mathrm{~cm} * 4.0 \mathrm{~cm} * 0.2 \mathrm{~cm}$ were polished to a mirror finish using emery sheets of various grades and degreased with trichloroethylene.

\section{Weight Loss Method}

Mild steel specimens in triplicate were immersed in $100 \mathrm{~mL}$ of the inhibited and uninhibited $0.5 \mathrm{~N} \mathrm{H}_{2} \mathrm{SO}_{4}$ solutions in the presence and absence of KI for two hours. The weight of each specimen before and after immersion was determined using shimadzu balance, model Ay 62. The inhibition efficiency (IE) was then calculated using the expression;

$$
I E \%=\left(\frac{W_{1}-W_{2}}{W_{1}}\right) \times 100
$$

Where $W_{1}$ and $W_{2}$ are the corrosion rates in the absence and presence of the inhibitor, respectively. 


\section{Electrochemical Impedance Measurements Impedance measurements}

The electrochemical impedance measurements were carried out using a Potentiostat/Galvanostat/FRA (PARSTAT 2273, Princeton Applied Research, USA). Data acquisition was performed utilizing the Power Suite software and analyzed using Zsimp Win software (version 3.21). A three electrode set up was employed with Pt foil as the auxiliary electrode and a saturated calomel electrode as the reference electrode. The Teflon coated mild steel rod, with the surface prepared as described in the weight loss experimental method, served as the working electrode. The measurements were carried out in the frequency range $10^{6}-10^{2}$ $\mathrm{Hz}$ at the open circuit potential by superimposing sinusoidal AC signal of small amplitude, $10 \mathrm{mV}$, after an immersion period of $30 \mathrm{~min}$ in the corrosive media. The double layer capacitance $\left(\mathrm{C}_{\mathrm{dl}}\right)$ and charge transfer resistance $\left(\mathrm{R}_{\mathrm{ct}}\right)$ were obtained from the impedance plots as described elsewhere. ${ }^{8}$ Because $\mathrm{R}_{\mathrm{ct}}$ is inversely proportional to corrosion current density, it was used to determine the inhibition efficiency (IE\%) using the relationship;

$$
I E \%=\frac{R_{c t}-R_{c t}^{o}}{R_{c t}} \times 100
$$

Where $\mathrm{R}_{\mathrm{ct}}$ and $\mathrm{R}_{\mathrm{ct}}^{\mathrm{o}}$ are the charge transfer resistance values in the inhibited and uninhibited solutions respectively.

\section{Polarization Measurements}

The potentiodynamic polarization curves were recorded using the same cell setup employed for the impedance measurements. The potentials were swept at the rate of $1.66 \mathrm{mV} / \mathrm{s}$, primarily from a more negative potential than $E_{\text {ocp }}$ to a more positive potential than $E_{\text {ocp }}$ through $E_{\text {corr }}$. The inhibition efficiencies were calculated using the relationship ${ }^{9}$

$$
I E \%=\frac{I_{\text {corr }}^{o}-I_{\text {corr }}}{I_{\text {corr }}^{o}} \times 100
$$

Where $\mathrm{I}_{\text {corr }}^{\mathrm{o}}$ and $\mathrm{I}_{\text {corr }}$ are the corrosion current densities in the absence and in the presence of inhibitor, respectively.

\section{RESULTS AND DISCUSSION}

\section{Analysis of Results of Mass Loss Method}

The corrosion rates and inhibition efficiency values, calculated using weight loss data, for various concentrations of ginger affinale extract in the presence and absence of $\mathrm{KI}$ for the corrosion of carbon steel in $0.5 \mathrm{~N} \mathrm{H}_{2} \mathrm{SO}_{4}$ solution are presented in Table 1. It is apparent that the inhi-
Table 1. Corrosion rates (CR) of carbon steel in the inhibited and uninhibited $0.5 \mathrm{~N} \mathrm{H}_{2} \mathrm{SO}_{4}$ solutions in the presence and absence of $\mathrm{KI}$

\begin{tabular}{ccccc}
\hline \multirow{2}{*}{$\begin{array}{c}\text { GA Extract } \mathrm{mL} \\
(\mathrm{ppm})\end{array}$} & \multicolumn{2}{c}{$\mathrm{KI}(0) \mathrm{ppm}$} & \multicolumn{2}{c}{$\mathrm{KI}(50) \mathrm{ppm}$} \\
\cline { 2 - 5 }$\left(\mathrm{mg} \mathrm{cm}^{-2} \mathrm{~h}^{-1}\right)$ & $\mathrm{IE} \%$ & $\begin{array}{c}\mathrm{CR} \\
\left(\mathrm{mg} \mathrm{cm}^{-2} \mathrm{~h}^{-1}\right)\end{array}$ & $\mathrm{IE} \%$ \\
\hline 0 & 112.81 & & 112.81 & \\
10 & 74.06 & 34.34 & 29.38 & 73.96 \\
25 & 69.06 & 38.78 & 25.00 & 77.84 \\
50 & 62.54 & 44.56 & 24.38 & 78.39 \\
100 & 55.31 & 50.97 & 13.28 & 88.22 \\
\hline
\end{tabular}

Immersion period: 2 hours; Inhibitor: Methanolic extract of Ginger affinale(GA)-KI.

bition efficiency increased with the increase in inhibitor concentration in the presence and absence of KI. This behavior can be explained based on the strong interaction of the inhibitor molecule with the metal surface resulting in adsorption. The extent of adsorption increases with the increase in concentration of the inhibitor leading to increased inhibition efficiency. The maximum inhibition efficiency was observed at an inhibitor concentration of $100 \mathrm{ppm}$. Generally, inhibitor molecules suppress the metal dissolution by forming a protective film adsorbed to the metal surface and separating it from the corrosion medium. The corrosion suppressing ability of the inhibitor molecule originates from the tendency to form either strong or weak chemical bonds with $\mathrm{Fe}$ atoms using the lone pair of electrons present on the $\mathrm{O}$ and $\pi$ electrons in benzene ring.

It is also seen from Table 1 that the rizhome extract of ginger affinale at 10 and $100 \mathrm{ppm}$ concentrations shows $34.34 \%$ and $50.97 \%$ inhibition efficiencies respectively, but these values increased to $73.96 \%$ and $88.22 \%$ after adding $50 \mathrm{ppm}$ of $\mathrm{KI}$ solution in $0.5 \mathrm{~N} \mathrm{H}_{2} \mathrm{SO}_{4}$ solutions containing 10 and $50 \mathrm{ppm}$ ginger extract respectively. The inhibition efficiency value also increased with the addition of $50 \mathrm{ppm}$ of KI solution for other inhibitor concentrations. This showed a good synergistic effect between ginger affinale and KI.

\section{Electrochemical Impedance Spectroscopic Measure- ments (EIS)}

Impedance spectra obtained for the corrosion of mild steel in the inhibited (100 ppm) and uninhibited $0.5 \mathrm{~N}$ $\mathrm{H}_{2} \mathrm{SO}_{4}$ solutions in the absence and presence of $\mathrm{KI}$ are shown in Fig. 1. The Nyquist plots are simple semi circles, free from inductive loops etc. The simple -R(CR)model describes best the situation at the metal/solution interface. However, the complex plane plots obtained aredepressed semi-circles, showing a non-ideal capacitive behavior of the electrochemical solid/liquid interface. ${ }^{10}$ This 


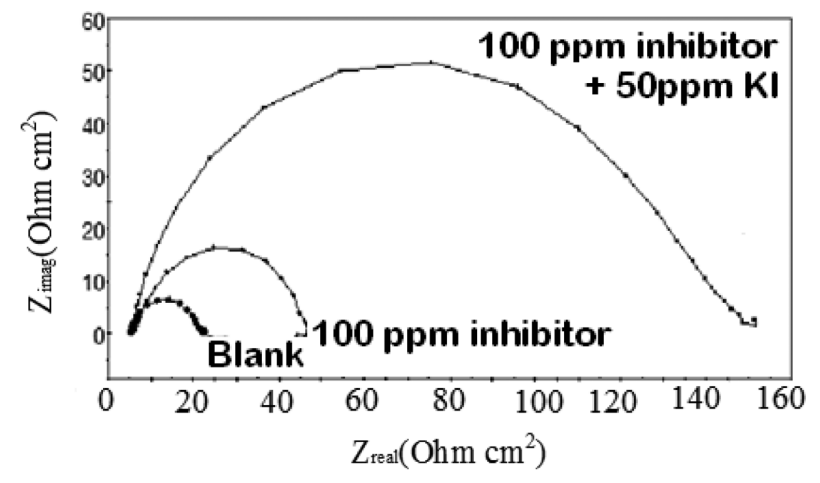

Figure 1. Impedance measurements of mild steel immersed in $0.5 \mathrm{~N} \mathrm{H}_{2} \mathrm{SO}_{4}$ solution in the absence and presence of inhibitors.

Table 2. Impedance parameters obtained from electrochemical impedance studies

\begin{tabular}{cccc}
\hline $\begin{array}{c}\text { Inhibitor concentration } \\
(\mathrm{ppm})\end{array}$ & $\begin{array}{c}\mathrm{R}_{\mathrm{ct}} \\
\mathrm{Ohm} \mathrm{cm}\end{array}$ & $\begin{array}{c}\mathrm{C}_{\mathrm{dl}} \\
\mu \mathrm{F}\end{array}$ & $\mathrm{IE} \%$ \\
\hline 0 & 17.2 & $9.2578 \times 10^{-3}$ & \\
100 & 47 & $5.7393 \times 10^{-5}$ & 63.40 \\
$100+50 \mathrm{ppm}(\mathrm{KI})$ & 151 & $1.786 \times 10^{-6}$ & 88.61 \\
\hline
\end{tabular}

capacitance dispersion at the solid surfaces can be attributed to the surface roughness, the degree of polycrystallinity, the chemical in homogeneities and anion adsorption. ${ }^{10}$ As presented in Table 2, with the increase in inhibitor concentration the $\mathrm{R}_{\mathrm{ct}}$ values increased, while the values of $\mathrm{C}_{\mathrm{dl}}$ decreased. The increase in $R_{\mathrm{ct}}$ values with an increase in inhibitor concentration is the result of an increase in the surface coverage by the inhibitor molecules; the increased surface coverage led to an increase in inhibitor efficiency. ${ }^{11}$ The decrease in $\mathrm{C}_{\mathrm{dl}}$ values with the the addition of inhibitor is due to the adsorption of the inhibitor molecules replacing water at the metal-solution interface that led to the decrease in local dielectric constant and/or an increase in the thickness ofthe electrical double layer. ${ }^{12}$ The further increase in inhibitor efficiency after adding $50 \mathrm{ppm} \mathrm{KI}$ solution to $0.5 \mathrm{~N} \mathrm{H}_{2} \mathrm{SO}_{4}$ solution containing $100 \mathrm{ppm}$ inhibitor is due to the synergistic effect between $\mathrm{KI}$ and the inhibitor molecules in the ginger extract.

\section{Potentiodynamic Polarization studies}

The polarization curves obtained for the corrosion of

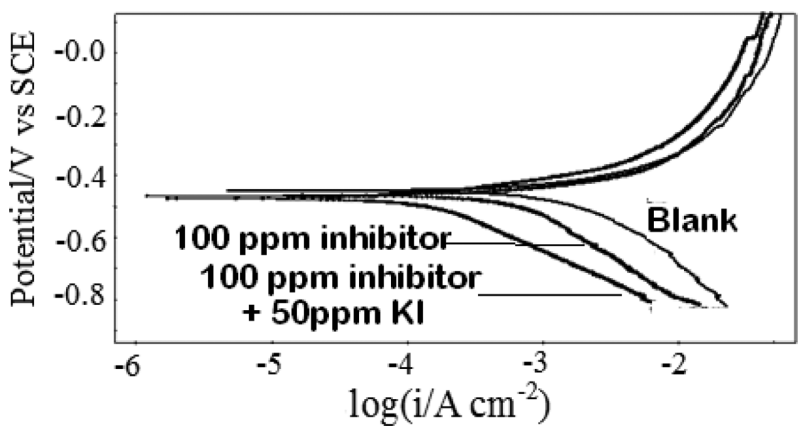

Figure 2. Potentiodynamic polarization curves of mild steel immersed in $0.5 \mathrm{~N} \mathrm{H}_{2} \mathrm{SO}_{4}$ solution in the absence and presence of inhibitors.

mild steel in the inhibited (100 ppm) and uninhibited $0.5 \mathrm{~N}$ $\mathrm{H}_{2} \mathrm{SO}_{4}$ solutions in the absence and presence of $\mathrm{KI}$ are shown in Fig. 2. Electrochemical parameters such as corrosion potential $\left(\mathrm{E}_{\text {corr }}\right)$, corrosioncurrent density $\left(\mathrm{I}_{\text {corr }}\right)$, cathodic and anodic tafel slopes $\left(\beta_{\mathrm{c}}\right.$ and $\left.\beta_{\mathrm{a}}\right)$ and percentage inhibition efficiency according to polarization studies are listed in Table 3. Here $\mathrm{I}_{\text {corr }}$ decreased with increasing inhibitor concentration. From these figures, it can be interpreted that the addition of this inhibitor to corrosive media changes the anodic and cathodic tafel slopes. The changes in slopes showed the influence of the inhibitor both in the cathodic and anodic reactions. However, the influence is more pronounced in the cathodic polarization plots compared to that in the anodic polarization plots. Even though $\beta_{\mathrm{c}}$ and $\beta_{\mathrm{a}}$ values (Table 3 ) change with an increase in inhibitor concentrations, a high $\beta_{\mathrm{c}}$ value indicates that the cathodic reaction is retarded to a higher extent than the anodic reaction. $^{13}$

From Fig. 2 it is also clear that the addition of the inhibitor shifts the cathodic curves to a greater extent toward the lower current density when compared to the anodic curves. The $\mathrm{E}_{\text {corr }}$ value is also shifted to the more negative side with an increase in the inhibitor concentration. These shifts<smiles>CCCCC[C@H](O)CC(=O)CCc1ccc(O)c(OC)c1</smiles>

Figure 3. Structure of gingerol.

Table 3. Corrosion parameters in the presence and absence of inhibitor obtained from polarization measurements

\begin{tabular}{cccccc}
\hline Inhibitor concentration $(\mathrm{ppm})$ & $-\mathrm{E}_{\text {corr }}(\mathrm{mV})$ & $\beta_{\mathrm{c}}(\mathrm{mV} /)$ & $\beta_{\mathrm{a}}(\mathrm{mV})$ & $\mathrm{I}_{\text {corr }} \times 10 * 6 \mu \mathrm{A}$ & $\mathrm{IE} \%$ \\
\hline 0 & 448 & 127 & 68 & 1.628 & \\
100 & 446 & 173 & 72 & 0.521 & 62.0 \\
$100+50$ ppmKI & 460 & 195 & 94 & 0.337 & 87.1 \\
\hline
\end{tabular}


can be attributed to the decrease in the rate of the hydrogen evolution reaction on the mild steel surface caused by the adsorption of the inhibitor molecule to the metal surface. ${ }^{14}$ It has been reported that a compound can be classified as an anodic and cathodic type inhibitor on the basis of shift of $E_{\text {corr }}$ value. If displacement of $E_{\text {corr }}$ value is greater than $85 \mathrm{mv}$, towards anode or cathode with reference to the blank, then an inhibitor is categorized as either anodic or cathodic type inhibitor otherwise inhibitor is treated as mixed type. ${ }^{17,18}$ In our study, maximum displacement in $E_{\text {corr }}$ value was around $12 \mathrm{mV}$, indicating the inhibitor is a mixed type and does not alter the reaction mechanism. The inhibition effect has occurred due to simple blocking of the active sites, thereby reducing available surface area of the corroding metal. ${ }^{15,16}$ The increase in inhibitor efficiency of inhibited (100 ppm) $0.5 \mathrm{~N} \mathrm{H}_{2} \mathrm{SO}_{4}$ solution for the corrosion of mild steel after adding $50 \mathrm{ppm} \mathrm{KI} \mathrm{shows} \mathrm{syn-}$ ergism between inhibitor molecules and $\mathrm{KI}$.

\section{SEM Analysis}

Figs. 4 and 5 show the surface analysis of metal by Scanning Electron Microscopy (Model-JEOL-JSM-6390). The surface morphological characteristics of the blank and inhibited mild steel were analyzed at magnification of 2.0 $\mathrm{KX}$ operated at an accelerating voltage of $15 \mathrm{kV}$. Scanning electron microscopy reveals that plant extract adsorbed on metal surface shows an excellent protection against corrosion attack. SEM provides a two-dimensional projection or a two-dimensional image of the sample.

\section{Active Principle for Corrosion}

In the present study the inhibition efficiency of ginger affinale can be attributed to the presence of 6-gingerol which is a major component and the other phenylpro-

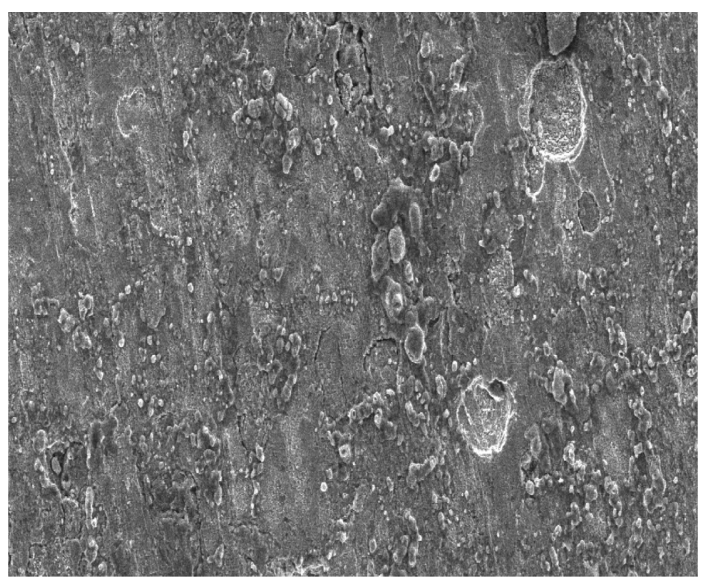

Figure 4. Surface analysis of mild steel blank.

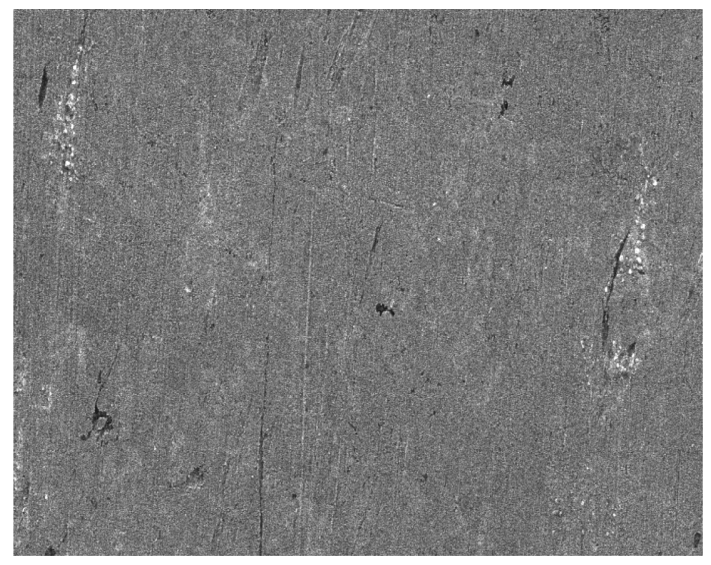

Figure 5. Surface analysis of mild steel in $0.5 \mathrm{~N} \mathrm{H}_{2} \mathrm{SO}_{4}$ solution with Ginger affinale extract.

panoid in the extract. ${ }^{19}$ Adsorption of the inhibitor molecules on the metal surface may be explained by the presence of an oxygen atom (a heteroatom), electrons of aromatic ring and electron donating groups. The hetro-atoms such as oxygen are the major adsorption center in organic compounds for its interaction with the metal surface..$^{20}$ The adsorption may also occur via electrostatic interaction between a negatively charged surface, which is provided by a specifically adsorbed anion $\left(\mathrm{Cl}^{-}\right)$on iron, and the positive charges on the inhibitor. ${ }^{21}$ This observation suggests that inhibitor molecules adsorb on the metal surface by blocking the active sites on the metal surface. ${ }^{22}$

\section{CONCLUSIONS}

The corrosion inhibition nature of ginger affinale extract was proved by Weight loss measurements, electrochemical impedance spectroscopic, potentiodynamic polarization and surface studies. The results obtained in these methods show the same trend. The results of weight loss measurements, electrochemical impedance and potentiodynamic polarization measurements consistently demonstrated that the ginger affinale is a good corrosion inhibitor for corrosion of mild steel in acid medium and the inhibitor efficiency increases with increase in inhibitor concentration.

The optimum inhibitor efficiency was observed at 100 ppm inhibitor concentration. The addition of $50 \mathrm{ppm}$ of KI to the inhibited solutions significantly increased the inhibitor efficiency. This could be attributed to the formation halide bridges between by iodide ion between metal surface and inhibitor molecules. The potentiodynamic polarization curves indicates that the inhibition is under mixed type. 
Acknowledgments. The publication cost of this paper was supported by the Korean Chemical Society.

\section{REFERENCES}

1. El-Etre, A. Y. Appl. Surf. Sci. 2006, 252, 8521-8525.

2. Bouyanzer, A.; Hammouti, B.; Majidi, L. Mater. Lett. 2006, 60, 2840-2843.

3. Benabdellah, M.; Benkaddour, M.; Hammouti, B.; Bendahhou, M.; Aouniti, A. Appl. Surf. Sci. 2006, 252, 6212-6217.

4. Chaieb, E.; Bouyanzer, A.; Hammouti, B.; Benkaddour, M. Appl. Surf. Sci. 2005, 246, 199-206.

5. Müller, B. Corros. Sci. 2002, 44, 1583-1591.

6. Zhao, Y.; Li, P.; Liang, Q.; Hou, B. Appl. Surf. Sci. 2005, 252, 1245-1253.

7. Etre, A. Y. El.; Abdallah, M.; El-Tantawy, Z. E. Corros. Sci. 2005, 47, 385-395.

8. Ashassi-Sorkhabi, H.; Shaabani, B.; Seifzadeh, D. Electrochim. Acta 2005, 50, 3446.

9. Shahin, M.; Bilgie, S.; Yilmaz, H. Appl. Surf. Sci. 2003, $195,1$.

10. Kumaravel, M.; Rameshkumar, S.; Subramanian, S. S.; Gowri, S.; Rajasekaran, N.; Selvaraj, A. Electrochemical Characterization of the Protective Film Formed by the Unsymmetrical Schiff's Base on the Mild Steel Surface in Acid Media. Electrochim. Acta 2011, 56, 3857-3863.

11. Hosseini, M.; Mertens, S. F. L.; Ghorbani, M.; Arshadi, M. R. Mater. Chem. Phys. 2003, 78, 800.

12. Behpour, M.; Ghoreishi, S. M.; Gandomi-Niasar, A.; Soltani,
N.; Salavati-Niasari, M. J. Mater. Sci. 2009, 44, 2444.

13. Sanghvi, R. A.; et al. Bull. Electrochem. 1999, 13, 358.

14. Prabhu, T. V.; Venkatesha, A. V.; Shanbhag, Praveen. B. M.; Kulkarni, G. M.; Kalkhambkar, R. G. Mater. Chem. Phys. 2008, 108, 283.

15. Selvarani, F. R.; Santhanalakshmi, S.; Sahayaraja, J. W.; Amalraj, A. J.; Rajendran, S. Bull. Electrochem. 2004, 20, 561-565.

16. Rajendran, S.; Reenkala, S. M.; Anthony, N.; Ramaraj, R. Corros Sci. 2002, 44, 2243-2252.

17. Scully, J. R. Polarization Resistance Method for Determination of Instantaneous Corrosion Rates. Corrosion 2000, $56,199$.

18. Silverman, D. C. Practical Corrosion Prediction Using Electrochemical Techniques. In Uhlig's Corrosion Handbook, 2nd ed.; Revie, R. W, Ed.; The Electrochemical Society: 2000.

19. Rahath Kubra, I.; Jagan Mohan Rao. L An Impression on Current Developments in the Technology, Chemistry, and Biological Activities of Ginger (Zingiber officinale Roscoe). Critical Reviews in Food Science and Nutrition 2012, 52, 651-688.

20. Rocca, E.; Rapin, C.; Mirambet, F. Corrosion Science 2004, 46, 653 .

21. Tebbji, K.; Oudda, H.; Hammouti, B.; Benkaddour, M.; Kodadi, M.; Ramdani, A. Colloids Surf., A 2005, 259, 143.

22. Ashassi-Sorkhabi, H.; Shaabani, B.; Seifzadeh, D. Electrochim. Acta 2005, 50, 3446. 